\title{
Rationing of Nursing Care and its Relationship to Nurse Practice Environment in a Tertiary Public Hospital
}

\author{
Reiner Lorenzo J. Tamayo, RN, ${ }^{1}$ Maria Khrizalyn Faye Quintin-Gutierrez, RN, ${ }^{2}$ \\ Mildred B. Campo, RN, ${ }^{3}$ Marivin Joy F. Lim, $\mathrm{RN}^{4}$ and Peter T. Labuni, RN ${ }^{5}$

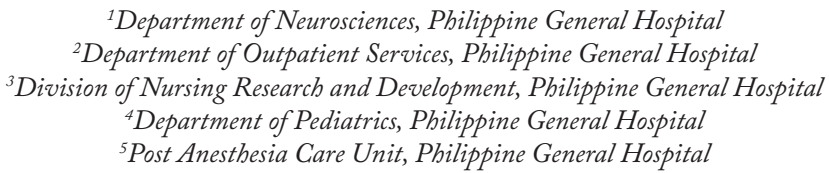

\section{ABSTRACT}

Objectives. The purpose of the study is to determine the level of rationing of nursing care and its relationship to nurses' perception of their practice environment.

Methods. The study employed a descriptive, cross-sectional study design. The Basel Extent of Rationing of Nursing Care (BERNCA) was administered to assess the level of care rationing while the Practice Environment Scale of the Nursing Work Index (PES-NWI) was used to describe nurses' practice environment. A total of 147 nurses participated in the study. Multiple regression analysis was conducted to determine the effect of various respondent characteristics and nurse practice environment on care rationing.

Results. Only practice environment total score was significantly associated with rationing of care total scores $(B=-0.20, p<0.05)$. Results of the regression show that for every unit increase in nurse practice environment total score, indicating a better work environment, there is a 0.20 unit decrease in rationing of nursing care total score, which indicated less rationing of care. Respondent characteristics are not significantly related.

Conclusion. Nurses most frequently rationed tasks in the areas of caring/support and monitoring. The less frequently rationed tasks involved medical, technical, and therapeutic aspects of care. The identification of rationing predictors can aid in determining starting points for hospital policy reforms. Prevalence levels can indicate when care rationing exceeds identified thresholds, if any. Nursing administrators can use implicit rationing of nursing care as a crucial indicator of the impact of strategies and changes in the nurse practice environment (e.g., changes in staffing levels, skill mix, and other resources).

Key Words: Health Care Rationing, Health Facility Environment, Nursing Care

Poster presented at the $53^{\text {rd }}$ Annual Convention of the Association of Nursing Service Administrators of the Philippines, March 12, 2020, Fiesta Pavilion, Manila Hotel, Manila.

Presented (Oral) at the $97^{\text {th }}$ Foundation Anniversary, $62^{\text {nd }}$ Nurses Week Celebration and Annual National Convention of the Philippine Nurses Association, October 22-24, 2019, Waterfront Cebu City Hotel, Lahug, Cebu City.

Presented (Oral) at the PGH Nursing Research Forum, October 23, 2019, Philippine General Hospital, Manila.

Corresponding author: Reiner Lorenzo J. Tamayo, RN Department of Neurosciences, Philippine General Hospital Taft Avenue, Ermita, Manila 1000, Philippines

Email: rjtamayo@up.edu.ph

\section{INTRODUCTION}

Rationing is defined as the controlled and mindful allocation of scarce resources and occurs wherein demand exceeds the need. ${ }^{1}$ In healthcare, rationing pertains to withholding, limiting, or omitting potentially beneficial treatments from some individuals on the grounds of the scarcity of resources such as time, skill or staffing mix. ${ }^{2}$ Rationing has become an unavoidable phenomenon because the need for healthcare is universal and limitless, whereas the resources to address this need are not.

Various reasons have been identified that may cause or impact the phenomenon of care rationing. Among 
which are reductions or inadequacies in staffing, along with increased care demands, more treatment options, and a more informed clientele who require more time and attention from care professionals. ${ }^{3}$

In nursing, implicit rationing, otherwise known as "missed care," "omitted care," or "nursing care left undone," refers to the failure to carry out necessary nursing care activities due to lack of resources. ${ }^{4}$ Based on observation, nurses are often forced to prioritize nursing activities that address the medical needs and promote the safety of their patients and leave out other activities such as documentation and emotional support.

Six reasons were found to be significant in contributing to missed nursing care. ${ }^{5}$ These reasons include an unexpected rise in patient volume and care acuity, heavy admissions or discharges, inadequate assistants, inadequate staff, medications not available when needed, and urgent/ emergent situations. ${ }^{5}$

Patient outcomes were seen to be negatively affected by the rationing of care. These patient outcomes included medication errors, urinary tract infections, patient falls, pressure injuries, critical incidents, quality of care and patient readmissions. ${ }^{6}$

Work environment, on the one hand, pertains to the characteristics of an organization that either facilitate or limits the practice of nursing. ${ }^{7}$ It includes aspects such as leadership, staffing, resources, and participation of nurses in hospital affairs or activities. Several studies have shown the connection between poor nurse work environment and nursing care rationing. ${ }^{8,9}$

Recent studies have explored the relationship of implicit rationing of nursing care and nurse work environment ${ }^{3,4,10}$ and have identified lack of time, staffing inadequacy, poor team dynamics, among others, as possible factors that impact nursing care rationing. ${ }^{9,10}$ It was suggested, therefore, that a better practice environment leads to a smaller volume of care that is left undone. ${ }^{5}$

Little is known about the occurrence of implicit rationing of nursing care in the Philippines as well as possible contributing factors. The relationship between the characteristics of the local nursing work environment and the rationing of care also remains unclear. To our knowledge, no study has been published yet that comprehensively examined the occurrence of implicit rationing of nursing care, possible contributing factors to rationing of care, and its relationship with the nurse practice environment in the Philippine context. Thus, this study was conducted to address this research gap.

\section{RESEARCH OBJECTIVES}

The primary purpose of the study is to explore (1) the level of nursing care rationing and (2) the relationship between rationing of nursing care and nurses' practice environment. In this study, it was hypothesized that nurse- related variables and elements of their practice environment affect the occurrence of implicit nursing care rationing.

Specifically, this study aimed to (a) determine the level of nursing care rationing, (b) explore the relationship between nursing care rationing and nurse-related variables (e.g., age, sex, length of service), and (c) explore the relationship between nursing care rationing and nurses' practice environment.

\section{MATERIALS AND METHODS}

\section{Study Design and Setting}

This study employed a descriptive, cross-sectional design. This type of study design was used to gather data that will characterize the occurrence of nursing care rationing at one point in time. Additionally, regression analysis was used in this study to find factors that affect the study variables. While regression analysis is not used to interpret cause-and-effect relationships between the variables, it can indicate how the variables are related or to what extent the variables are associated with each other. Due to the nature of the study design, data from the participants are useful for establishing preliminary evidence of a relationship among the study variables.

The study was conducted in a university tertiary public hospital located in the City of Manila, Philippines. It is considered one of the biggest modern tertiary hospitals in the Philippines and has an authorized capacity of 1,500 beds - with 1,000 beds dedicated to indigent patients, and the remaining 500 beds designated for private patients. The hospital, operated by a state university, is considered the largest training hospital in the country and caters to an average of 600,000 patients annually. The usual nurse-topatient ratio in general wards is $1: 20$, above the standard set by the Department of Health, which is 1:12.

Due to the hospital's modern facilities and capacity to handle complex medical cases, many Filipinos choose to seek to consult and avail medical treatment in this hospital. This hospital was chosen as the study site because it has the conditions commonly cited as reasons for the occurrence of nursing care rationing. These reasons include lack of supply, inadequate staff, and high patient workload. In a country where access to health care remains a public health challenge, this hospital in Manila has to contend with the government's limited resources in the delivery of health care services in the context of a growing demand for better health.

\section{Sample and Sampling Design}

The study participants are Filipino nurses working in this hospital but limited to those involved in direct patient care in charity/service wards, pay/private wards, and intensive/ critical care units. Participants' age should be at least 21 years old, and he/she should have been working in this hospital for more than six months at the time of data collection. Nurses in administrative units and other specialty units, such as the hemodialysis unit, operating room complex, and emergency 
services were not included. Nurses without permanent employment status were also excluded from the study.

Proportional stratified sampling design was utilized. To achieve a representative sample for all clinical units, nurses in private and charity wards were initially grouped into clusters. For charity wards, nurses were clustered based on clinical specialty (i.e., Medicine, Surgery, Obstetrics and Gynecology, Pediatrics, Neurology and Behavioral Medicine, and Rehabilitation Medicine). For private wards, nurses were clustered based on their unit's floor location (i.e., $4^{\text {th }}$ floor, $5^{\text {th }}$ floor, $6^{\text {th }}$ floor, $7^{\text {th }}$ floor). Critical care units were not clustered. The clusters were eventually grouped into three strata according to the area of work: charity wards, pay wards, and critical care units. The latest data on the number of nurses in the different clinical areas were collected from the hospital's Division of Nursing Research and Development. The number of nurses in the strata and cluster to be selected was determined by using the stratified sample formula. Simple random sampling was conducted in each cluster to meet the target sample size. Using GPower 3.1 , with a moderate effect size of 0.3 , alpha of 0.05 , and power of $95 \%$, the target sample size was at least 111 .

\section{Instruments}

The following instruments were used: Respondent Profile Questionnaire, Basel Extent of Rationing of Nursing Care (BERNCA), and Practice Environment Scale of the Nursing Work Index (PES-NWI). BERNCA is an instrument developed to measure the implicit rationing of nursing care. The instrument was used in the Swiss part of the International Hospital Outcomes Study in which implicit rationing of nursing care was explored. The final version of the questionnaire included 20 questions that were divided into five dimensions: (a) Activities of Daily Living, (b) Caring and Support, (c) Rehabilitation and Instruction Education, (d) Monitoring and Safety, and (e) Documentation. Using a four-point Likert scale (never $=0$, rarely $=1$, sometimes $=2$, often $=3$ ), nurses were asked how often they had been unable to carry out the listed nursing tasks in the previous seven working days. The inter-item correlation mean of 0.39 (range: $0.19-0.63$ ) indicated the good consistency of the scale. Cronbach`s alpha was 0.93 . Low scores on the BERNCA instrument suggest low levels of rationing. ${ }^{11}$

The PES-NWI was developed as a composite measure of the nursing practice environment. The final version of the instrument was composed of 31 items under five subscales: (a) Nurse Participation in Hospital Affairs, (b) Nursing Foundations for Quality of Care, (c) Nurse Manager Ability, Leadership, and Support of Nurses, (d) Staffing and Resource Adequacy, and (e) Collegial Nurse-Physician Relations. All subscales had a Cronbach's alpha equal or greater than 0.80 except for the fifth subscale $(\alpha=0.71)$. The inter-item correlations ranged from 0.64 to 0.91 , and the intraclass correlations ranged from 0.88 to $0.97 . .^{12,13,14}$
Higher scores on the PES-NWI instrument suggest a better work environment. ${ }^{12}$

The copyright holders of both instruments have permitted the authors to use the tools in this study provided that the results are shared with them at the end of the study, and that proper citation was observed.

\section{Data Collection}

Data to address research questions were collected using a self-administered questionnaire. Questionnaires and other data collection tools used in past studies on rationing of nursing care and nurse practice environment were considered in the design of the questionnaire. The initial version of the questionnaire was pre-tested in a group of ten nurses, other than the intended participants. A group of nurses from service wards, pay wards, and intensive care units were randomly selected and invited as participants of the pretest. After the pre-test, clarity, appropriateness, acceptability (gender and cultural sensitivity) of questions and response categories, and visual appeal of the questionnaire were determined through a focus group discussion. The final version of the questionnaire reflected the suggestions of the participants of the pre-test and focus group discussion.

Each investigator was assigned to a cluster. Before data collection, investigators informed the head nurse or charge nurse of the clinical unit about the conduct of the research in the hospital. The investigators informed the nurses who met the selection criteria about the study and entertained questions, if any. Informed consent forms were distributed to the intended participants. Nurses who agreed to participate in the study and signed the consent form were given the option to fill-out the self-administered questionnaire within the initial face-to-face encounter with one of the investigators or to fill it out completely at a later time. For some participants, a follow-up date was identified, during which the researcher personally collected the filled-out questionnaire. Each participant was given 10-15 minutes of his/her time to answer the self-administered questionnaire. The study lasted for six months, and the participants were given the option to stop participating even if they agreed earlier.

\section{Data Processing and Storage}

Investigators checked the completeness and legibility of responses to items in the questionnaire at the following levels: (1) upon submission, (2) prior data encoding, and (3) after data encoding. Missing, illegible, inconsistent, and out-of-range entries were rectified by follow-up queries to participants to the extent permitted by timelines and resources, and availability and cooperation of respondents. If follow-up correspondence did not rectify missing, illegible, inconsistent, and out-of-range entries, data imputation was not performed.

Forms and other output relevant to the study were kept in a steel cabinet with a padlock. The key was kept by one 
of the investigators. Digital copies of all files relevant to the study were stored in computers dedicated to the study with periodic creation of back-up. Only the investigators were granted access through a password to all materials relevant to the study. Filled out questionnaires and other studyrelated documents will be shredded after two years from publication. All digital copies will be permanently deleted after two years from publication.

\section{Data Analyses}

Mean and standard deviation were computed for quantitative variables. Counts and relative frequencies were determined for categorical variables. Inferential statistics was employed to test whether there is a significant difference for each of the demographic variables among individual subscales. Regression analysis was employed to determine relationship among factors. All statistical analyses were carried out using Stata; statistical significance was set at $\mathrm{p}<$ 0.05 for all analyses.

\section{Ethical Considerations}

All research activities and elements were directed by the guidelines set by the University of the Philippines Manila Research Ethics Board and the Expanded Hospital Research Office. The study protocol was submitted for review to the Division of Nursing Research and Development and Expanded Hospital Research Office prior to the conduct of the study. The study obtained ethics approval from the University of the Philippines Manila Research Ethics Board with protocol number UPMREB 2018-315-01.

Participants who met the selection criteria were asked to sign an informed consent form. The consent form contained provisions on voluntary participation, withdrawal, privacy, and confidentiality. No identifiable information was collected from the participants except for demographic data. Each participant was assigned a unique code and was referred to in the study documents through the use of this code.

There were no other foreseeable risks associated with participating in the study except for psychological risks. Some items of the survey questionnaire may be related to personal experiences, and answering such questions may result in emotional distress. To mitigate this risk, participants were informed of available services to address emotional distress brought about by participating in the study. The principal investigator served as the primary contact person for participants needing support or referral. The principal investigator's contact number, as well as other contact information, were provided to the participants. A nurse trained on stress debriefing was made available to the participants.

There were no expenses incurred by the participants in the course of the study. There were no direct benefits and monetary compensation for the participants.

\section{RESULTS}

\section{Characteristics of Respondents}

Out of 159 nurses invited, only 147 participated in the study yielding a response rate of $92.4 \%$ (Table 1 ). Majority of the respondents are female $(\mathrm{n}=93,75.6 \%)$ and single $(\mathrm{n}$ $=73,59.3 \%)$. Almost half $(\mathrm{n}=61,49.6 \%)$ of the respondents are nurses in the charity or service wards, and have been working in the hospital for less than five years $(n=57$, 46.3\%). Only three respondents (2.4\%) have completed their graduate degrees.

Table 1. Respondents' characteristics ( $N=123)$

\begin{tabular}{|c|c|c|}
\hline Variable & Frequency & Percent \\
\hline \multicolumn{3}{|l|}{ Sex } \\
\hline Male & 30 & 24.4 \\
\hline Female & 93 & 75.6 \\
\hline \multicolumn{3}{|l|}{ Age (in years) } \\
\hline $20-30$ & 60 & 48.8 \\
\hline $31-40$ & 35 & 28.5 \\
\hline $41-50$ & 25 & 20.3 \\
\hline$>50$ & 3 & 2.4 \\
\hline \multicolumn{3}{|l|}{ Marital Status } \\
\hline Single & 73 & 59.3 \\
\hline Married & 46 & 37.4 \\
\hline Widowed & 1 & 0.8 \\
\hline Separated & 3 & 2.4 \\
\hline \multicolumn{3}{|l|}{ Area of assignment } \\
\hline Medicine & 18 & 14.6 \\
\hline Surgery & 26 & 21.1 \\
\hline OB-Gyne & 13 & 10.6 \\
\hline Pediatrics & 18 & 14.6 \\
\hline Neuro-Behavioral & 10 & 8.1 \\
\hline Rehabilitation & 3 & 2.4 \\
\hline Mixed & 35 & 28.5 \\
\hline \multicolumn{3}{|l|}{ Service Type } \\
\hline Charity/Service & 61 & 49.6 \\
\hline Pay/Private & 35 & 28.5 \\
\hline Intensive Care & 27 & 22.0 \\
\hline \multicolumn{3}{|c|}{ Length of service in the hospital } \\
\hline $6 \mathrm{mos}-5 \mathrm{yrs}$ & 57 & 46.3 \\
\hline$>5$ yrs -10 yrs & 30 & 24.4 \\
\hline$>10 \mathrm{yrs}$ & 36 & 29.3 \\
\hline \multicolumn{3}{|l|}{ Length of service in the unit } \\
\hline 6 mos -5 yrs & 72 & 58.5 \\
\hline$>5$ yrs -10 yrs & 28 & 22.8 \\
\hline$>10$ yrs & 23 & 18.7 \\
\hline \multicolumn{3}{|l|}{ Education } \\
\hline BS & 120 & 97.6 \\
\hline MAN/MS & 3 & 2.4 \\
\hline $\mathrm{PhD}$ & 0 & 0 \\
\hline
\end{tabular}




\section{Rationing of Nursing Care}

The mean composite score for BERNCA was 1.04 $(\mathrm{SD}=0.65)($ Table 2$)$. This composite score indicates that when asked how often they were unable to perform specific nursing tasks, nurses reported this occurred 'rarely.'

The following were the most frequently rationed care reported by nurses. Among the nurses, 58.5\% ( $\mathrm{n}=72$ ) reported not being able to assist a patient with a necessary sponge bath or skincare (Table 3). About 56\% ( $\mathrm{n}=69)$ reported that a physician either did not come in person or took a long time to arrive after being called because of an acute or sudden change in a patient's condition. Almost half of the nurses $(n=61)$ reported that they sometimes could not perform a necessary oral or dental hygiene to a patient.

In comparison, 106 nurses (86.2\%) reported that they rarely could not prepare a patient or their family for his/ her hospital discharge. Moreover, 81.3\% $(\mathrm{n}=100)$ of the respondents reported that they rarely could not wash or disinfect their hands adequately. The same number of nurses $(n=100)$ reported that they rarely had to restrain or give patients sedatives.

\section{Nurse Practice Environment}

The mean composite score for NPE-NWI was 2.87 $(\mathrm{SD}=0.58)$, indicating an above-average combined score (Table 2). Based on the three-level classification used in interpreting composite subscale scores of the NPE-NWI, an above-average score indicates a favorable work setting. The subscale Nurse Foundations for Quality of Care had the highest mean score $(\mathrm{M}=3.30, \mathrm{SD}=0.67)$ followed by Nurse Manager Ability, Leadership, and Support $(\mathrm{M}=3.27, \mathrm{SD}=$ 0.79).; and Collegial Nurse-Physician Relations $(\mathrm{M}=3.27$, $\mathrm{SD}=0.72)$. The subscale Staffing and Resource Adequacy had the lowest mean score $(\mathrm{M}=2.65, \mathrm{SD}=0.98)$.

Ninety-six percent $(n=118)$ of the respondents agreed that there is active staff development or continuing education programs for nurses in their current job (Table 4). More than $95 \%(n=117)$ of the respondents agreed that staff nurses have the opportunity to serve in the hospital nursing committees. The same number $(n=117)$ of nurses agreed that they are working with clinically competent nurses.

In contrast, 70 (56.95\%) of the respondents disagreed that there are enough nurses to provide quality patient care. About 54\% $(n=66)$ disagreed that there is enough staff to get the work done.

\section{Relationship of Practice Environment and Care Rationing}

A multiple regression analysis was conducted to determine the effect of various respondent characteristics and nurse practice environment (total score) on care rationing (total score). A significant regression equation was found $(\mathrm{F}(20,102)=2.66, \mathrm{p}<0.05)$, with an $\mathrm{R} 2$ of 0.343 .

Only total practice environment scores are significantly associated with total care rationing scores $(B=-0.20$,
Table 2. Descriptive statistics of main variables

\begin{tabular}{lcc}
\multicolumn{1}{c}{ Variable } & M & SD \\
BERNCA & & \\
Composite & 1.04 & 0.65 \\
Activities of Daily Living & 1.15 & 0.81 \\
Caring-Support & 1.16 & 0.94 \\
Rehabilitation-Instruction-Education & 0.82 & 0.73 \\
Monitoring-Safety & 1.03 & 0.65 \\
Documentation & 1.05 & 0.88 \\
\hline PES-NWI & & \\
Composite & 2.87 & 0.58 \\
Nurse Participation in Hospital Affairs & 3.19 & 0.67 \\
$\quad$ Nursing Foundations for Quality of Care & 3.30 & 0.63 \\
Nurse Manager Ability, Leadership, and & 3.27 & 0.79 \\
$\quad$ Support of Nurses & & \\
Staffing and Resource Adequacy & 2.65 & 0.98 \\
Collegial Nurse-Physician Relations & 3.27 & 0.72 \\
\hline
\end{tabular}

Table 3. Top ten most frequently rationed care reported by nurses

\begin{tabular}{lcc}
\multicolumn{1}{c}{ Care element } & $\mathbf{n}$ & $\%$ \\
\hline Assist a patient in sponge bath or skin care & 72 & 58.5 \\
Physician did not come or took long time to arrive & 69 & 56.1 \\
Perform oral or dental hygiene to a patient & 61 & 49.6 \\
$\begin{array}{l}\text { Keep patient who rung for a nurse waiting longer } \\
\text { than } 5 \text { minutes }\end{array}$ & 56 & 45.5 \\
$\begin{array}{l}\text { Perform activating or rehabilitating care } \\
\text { Review documentation at the beginning of the shift }\end{array}$ & 50 & 40.7 \\
$\begin{array}{l}\text { Mobilize or change the position of a patient } \\
\text { Offer emotional or psychosocial support to a patient }\end{array}$ & 48 & 39.8 \\
$\begin{array}{l}\text { Monitor a patient as closely as had been prescribed } \\
\text { or as felt necessary }\end{array}$ & 42 & 34.1 \\
$\begin{array}{l}\text { Have necessary conversation with a patient or } \\
\text { his/her family }\end{array}$ & 41 & 33.3 \\
\hline
\end{tabular}

$n$ - number of nurses

Table 4. Top organizational characteristics that most nurses believe are present in their current job

\begin{tabular}{lcc}
\hline \multicolumn{1}{c}{ Organizational characteristics } & $\mathbf{n}$ & $\%$ \\
\hline $\begin{array}{l}\text { Active staff development or continuing education } \\
\text { programs }\end{array}$ & 118 & 95.9 \\
$\begin{array}{l}\text { Opportunity to serve in hospital and nursing } \\
\text { committees }\end{array}$ & 117 & 95.1 \\
Working with nurses who are clinically competent & 117 & 95.1 \\
$\begin{array}{l}\text { High standards of nursing care are expected by the } \\
\quad \text { administration }\end{array}$ & 116 & 94.3 \\
$\begin{array}{l}\text { Active quality assurance program } \\
\text { Physicians and nurses have good working relationships }\end{array}$ & 113 & 91.9 \\
$\begin{array}{l}\text { Career development/clinical ladder opportunity } \\
\text { Nursing care is based on nursing, rather than a }\end{array}$ & 112 & 90.2 \\
$\quad$ medical model & 111 & 39.0 \\
A chief nursing officer who is highly visible and & 110 & 89.4 \\
$\quad$ accessible to staff & 110 & 89.4 \\
\hline A lot of teamwork between nurses and physicians & &
\end{tabular}

$n$ - number of nurses 
$\mathrm{p}<0.05)$. Results of the regression showed that for every unit increase in nurse practice environment total score, indicating a better work environment, there was a 0.20 unit decrease in rationing of nursing care total score, indicating less rationing of care. Respondent characteristics were not significantly related.

\section{DISCUSSION}

\section{Level of Care Rationing}

The increasing demands on nursing staff, vis-a-vis the number of nurses, have significantly reduced the time with which nurses-in-charge attend to the needs of their patients. As a result, nurses are often forced to ration the nursing care that they provide to each patient while ensuring patient safety.

Comparable with the results of a Swiss study, ${ }^{15}$ the measured level of rationing was rather low. Conversely, there was considerable variability in rationing frequencies among the nursing tasks included in the BERNCA. This study found that nurses most frequently rationed tasks in the areas of caring/support and monitoring. The less frequently rationed tasks involved medical, technical, and therapeutic aspects of care.

The most frequently rationed care included sponge baths or skincare and oral/dental hygiene. This finding was similar to the findings of other studies where routine hygiene was one of the most frequently care left undone..$^{10,16}$ Additionally, activities such as reviewing documentation, providing emotional or psychological support, assisting the patient during ambulation or positioning, and providing timely response to the patient need/call were also among the most frequently rationed care. ${ }^{10,16}$

Vital signs monitoring is a core function of a nurse and is an essential part of patient assessment that is done no more than every eight hours. Other studies have reported vital signs monitoring as one of the least rationed care. ${ }^{10,16}$ It is surprising for this study to find that more than $34 \%$ of nurses reported monitoring of patients' vital signs as one of the frequently rationed care.

It should be noted, however, that medical interns are sometimes asked by their residents to help monitor patients' vital signs. As such, vital signs monitoring may not be rationed by nurses but delegated to another member of the health care team. This hospital policy could explain why many nurses reported rationing vital signs monitoring.

Rationing of monitoring and communication, however, could lead to safety and quality of care issues. Monitoring and communication are care elements that allow the early detection of changes in the condition of patients. Missing early objective and subjective cues could potentially increase workload due to increased care needs of patients. ${ }^{4}$

These findings suggest that nurses have developed an informal hierarchical system of nursing tasks or procedures which is used to prioritize nursing care when resources are scarce to provide the necessary care to patients. These rationing patterns indicate that nurses favor completing activities that were directed towards immediately meeting their patients' physiologic needs over other activities that are not considered urgent. ${ }^{16}$ Due to time constraints, nurses try to maintain or ensure first the safety and physical wellbeing of their patients. Consequently, psychosocial care, and those tasks for which the required time cannot be ascertained or whose potential effects are less direct are more often left undone. However, this hierarchical prioritization system requires further exploration, possibly through a qualitative study design.

\section{Factors Related to Care Rationing}

In this study, regression analysis was used to determine the association between nurse characteristics and implicit rationing of care. The regression model showed that respondent characteristics were not significantly associated with rationing of care.

Previous studies have also explored the relationship of implicit rationing of nursing care and nurse work environment ${ }^{4,8,10}$ and have identified several work environment characteristics as possible factors influencing nursing care rationing. These work environment characteristics include lack of time, inadequate nurse staffing, teamwork, and lack of nursing skill and knowledge. ${ }^{9,10}$

Among the five dimensions of the nurse practice environment, it was apparent that the Staffing and Resource Adequacy dimension had the most potential for improvement. This result is contrary to the basic elements mentioned by the International Council of Nurses of a Positive Practice Environment which include safe staffing levels, and access to adequate equipment, supplies, and support staff. ${ }^{17}$

The findings of this study were partly congruent with the findings of a national study on nurses' work environment where the authors found that the lowest responses were in the Physiologic and Safety Needs clusters of the Filipino nurse practice environment. ${ }^{18}$ The Physiologic Needs variable cluster reflects work status incongruence, poor work hours, and reduced benefits. Unmet Safety Needs, on the one hand, are those that reflect poor organization support, and unjust work environment such as poor nurse-patient ratio, levels of patient acuity, lack of available support for the needs of nurses, and the exclusion of nurses in decision-making for their own welfare. ${ }^{18}$

A healhy relationship has been previously found between nurse staffing levels and the prevalence of care being left undone. ${ }^{9}$ As the number of patients assigned per nurse decreases, so does the occurrence of missed care. Fewer missed nursing care activities, as well as fewer odds of missing any care, were noted for nurses caring for the fewest patients compared to nurses caring for the greatest number of patients. It was noted that $78 \%$ in the best-staffed environments reported some incidence of missed care compared to the $90 \%$ reported in the areas with lower staffing levels. ${ }^{9}$ 
The Staffing and Resource Adequacy dimension of the Nurse Practice Environment includes items such as "Enough staff to get the work done," and "Enough registered nurses to provide quality patient care." The findings of this study suggested that better staffing levels and adequate resources have the potential to reduce care rationing. It is appropriate, however, for future research to use more refined measures of nurse staffing. Nursing hours per patient day can be used to create an evidence-based staffing plan as it is a valid measure of the number of nursing staff needed in a unit. ${ }^{19}$ Using this variable, a significant association was found between a higher number of hours per patient day and the incidence of missed nursing care. ${ }^{20}$

In this study, the nurse practice environment was found to be associated with the rationing of nursing care. Several studies collectively suggest that a better practice environment leads to better health care delivery, hence a smaller volume of undone, missed, or rationed care. ${ }^{9,10}$ Nurses who work in areas viewed as more positive practice environments reported fewer elements of missed care and had fewer odds of missing any care. There was a reported $79 \%$ incidence of missed nursing care in the best practice environments compared to the $92 \%$ in worst practice environment areas. ${ }^{9}$

Identifying unit or system-based strategies to ensure sufficiency of material and psychosocial support was found to decrease missed care. Ensuring adequate supplies, equipment, and resources (physical), as well as ensuring balanced assignments and improving team performance (psychosocial) were some of the strategies identified. ${ }^{10}$

\section{Limitations of the Study}

This study was done in a government-run tertiary hospital. As such, conclusions made in the study are not transferable to other populations, such as those nurses working in private hospitals. Although practice environments differ in private and public hospitals, nurses in private hospitals may still relate their experiences to some elements of this study. Moreover, the measure of rationing of nursing care was based on the subjective impression of nurses about what qualifies as necessary nursing care and whether it was provided or not. This could be influenced by individual values that were not taken into consideration in this study. Finally, the cross-sectional design of the study does not permit causal relationships to be assumed.

\section{CONCLUSION, RECOMMENDATIONS, AND IMPLICATIONS TO PRACTICE}

This study provides knowledge about the levels of rationing of care in a university tertiary hospital in Manila, Philippines. The results showed variability in the prevalence among the nursing tasks included in the BERNCA. This finding indicated that when confronted with resource inadequacy, nurses prioritized nursing tasks or left some care undone. It appeared that medical, technical, and therapeutic aspects of care were generally given the highest priority. In contrast, psychosocial and caring/support aspects of care were the most frequently rationed by nurses.

Because rationing can never be entirely prevented, it was suggested for the hospital to define the threshold above, which rationing negatively affected patient outcomes. ${ }^{19}$ The identification of rationing predictors can aid in determining starting points for hospital policy reforms. Prevalence levels can indicate when care rationing exceeds identified thresholds. ${ }^{19}$ These data can be used by nursing administrators to use implicit rationing of nursing care as a crucial indicator of the impact of strategies and changes in the nurse practice environment (e.g., changes in staffing levels, skill mix, and other resources).

With those as mentioned earlier, one obvious kick-off point would be for the hospital to invest in improving the quality of the nurse practice environment. In particular, the hospital should ensure the adequacy of nurse staffing and other essential resources. It follows that the improvement of nurse practice environment, specifically staffing and resource adequacy, leads to reduced rationing levels, and to a greater extent, the risk of adverse patient- and nurse-sensitive outcomes. Finally, regular surveys of rationing of nursing care can eventually provide data trends that could inform policy discussions on minimum staffing levels and nurseto-patient ratios necessary to achieve the desired nurse and patient outcomes.

Future studies can (1) explore the views of patients on implicit rationing of care, (2) examine the associations between implicit rationing of nursing care and nurse-and patient-sensitive outcomes, (3) identify rationing of care thresholds that have negative consequences for nurses and patients, (4) and explore views of nurses on the reasons behind the occurrence of implicit rationing of nursing care through a qualitative research design.

\section{Acknowledgments}

The authors would like to acknowledge Mr. Dan Louie Renz Tating and Nightingale Research Solutions for their assistance in statistical analyses.

\section{Statement of Authorship}

All authors participated in data collection and analysis, and approved the final version submitted.

\section{Author Disclosure}

All authors declared no conflicts of interest.

\section{Funding Source}

This study was funded by the Expanded Hospital Research Office of the Philippine General Hospital.

\section{REFERENCES}

1. Reinhardt UE. Rationing health care: what it is, what it is not, and why we cannot avoid it. The Baxter health policy review. 1996;2:63-99. 
2. Scheunemann LP, White DB. The ethics and reality of rationing in medicine. Chest. 2011 Dec 1;140(6):1625-32.

3. Papastavrou E, Andreou P, Tsangari H, Merkouris A. Linking patient satisfaction with nursing care: the case of care rationing-a correlational study. BMC nursing. 2014 Dec;13(1):26.

4. Zúñiga F, Ausserhofer D, Hamers JP, Engberg S, Simon M, Schwendimann R. Are staffing, work environment, work stressors, and rationing of care related to care Workers' perception of quality of care? A cross-sectional study. Journal of the American Medical Directors Association. 2015 Oct 1;16(10):860-6.

5. Winsett RP, Rottet K, Schmitt A, Wathen E, Wilson D, Group MN. Medical surgical nurses describe missed nursing care tasksEvaluating our work environment. Applied Nursing Research. 2016 Nov 1;32:128-33.

6. Recio-Saucedo A, Dall'Ora C, Maruotti A, Ball J. Briggs J, Meredith P, Griffiths, P. (2018). What impact does nursing care left undone have on patient outcomes? Review of the literature. Journal of Clinical Nursing, 27(11-12), 2248-59

7. Kirwan M, Matthews A, Scott PA. The impact of the work environment of nurses on patient safety outcomes: a multi-level modeling approach. International journal of nursing studies. $2013 \mathrm{Feb}$ 1;50(2):253-63.

8. Papastavrou E. The ethical complexities of nursing care rationing. Health Science Journal. 2013 Oct 1;7(4):346.

9. Ball JE, Murrells T, Rafferty AM, Morrow E, Griffiths P. 'Care left undone' during nursing shifts: associations with workload and perceived quality of care. BMJ Qual Saf. 2014 Feb 1;23(2):116-25.

10. Schubert M, Glass TR, Clarke SP, Schaffert-Witvliet B, De Geest S. Validation of the Basel extent of rationing of nursing care instrument. Nursing research. 2007 Nov 1;56(6):416-24.

11. Nunez F. Examining the Cultural Measurement Equivalence of the Practice Environment Scale-Nursing Work Index (Doctoral dissertation, University of Kansas).

12. Lake ET. Development of the practice environment scale of the Nursing Work Index. Research in nursing \& health. 2002 Jun;25(3):176-88.
13. Warshawsky NE, Havens DS. Global use of the practice environment scale of the nursing work index. Nursing research. 2011 Jan;60(1):17.

14. Schubert M, Ausserhofer D, Desmedt M, Schwendimann R, Lesaffre E, Li B, De Geest S. Levels and correlates of implicit rationing of nursing care in Swiss acute care hospitals - a cross-sectional study. International Journal of Nursing Studies. 2013 Feb 1;50(2):230-9.

15. Jones TL. A descriptive analysis of implicit rationing of nursing care: frequency and patterns in Texas. Nursing Economics. 2015 May 1;33(3):144.

16. International Council of Nurses, International Hospital Federation, International Pharmaceutical Federation, World Confederation for Physical Therapy, World Dental Federation, World Medical Association (WHPA). Fact Sheet: Positive practice environment for health care professionals [Internet]. Geneva: WHPA; 2008 [cited 2016 May 18]. Available from: http://www.whpa.org/ppe_fact_health_pro. pdf

17. Dones L, Paguio J, Bonito S, Balabagno A, Pagsibigan J. Work environment of nurses in the Philippines: A preliminary study. Philipp J Nurs. 2016;86:4-10.

18. Van den Heede K, Clarke SP, Sermeus W, Vleugels A, Aiken LH. International experts' perspectives on the state of the nurse staffing and patient outcomes literature. Journal of Nursing Scholarship. 2007 Dec;39(4):290-7.

19. Kalisch BJ, Tschannen D, Lee KH. Do staffing levels predict missed nursing care?. International Journal for Quality in Health Care. 2011 Apr 11;23(3):302-8.

20. Schubert M, Clarke SP, Glass TR, Schaffert-Witvliet B, De Geest S. Identifying thresholds for relationships between impacts of rationing of nursing care and nurse-and patient-reported outcomes in Swiss hospitals: a correlational study. International journal of nursing studies. 2009 Jul 1;46(7):884-93. 